\title{
3. Characterising academic information systems in Australia: developing and evaluating a theoretical framework
}

\author{
Gail Ridley \\ IT Control Research Group \\ School of Accounting and Corporate Governance \\ University of Tasmania
}

\begin{abstract}
The study reported in this monograph aims to investigate the state of the information systems (IS) academic discipline in Australia from a historical and current perspective, collecting evidence across a range of dimensions. To maximise the strategic potential of the study, the results need to be capable of integration, so that the relationships within and across the dimensions and geographical units are understood. A meaningful theoretical framework will help relate the results of the different dimensions of the study to characterise the discipline in the region, and assist in empowering the Australian IS research community. This chapter reviewed literature on the development of disciplines, before deriving a theoretical framework for the broader study reported in this volume. The framework considered the current and past state of IS in Australian universities from the perspective of the development of a discipline. The components of the framework were derived and validated through a thematic analysis of the IS and non-IS literature. This chapter also presents brief vignettes of the development of two other related disciplines. The framework developed in this chapter, which has been guided partly by Whitley's theory of scientific change, has been used elsewhere to analyse data collated from the Australian states and the Australian Capital Territory. The degree of variation in Australian IS as an indication of its 'professionalisation', the nature of its body of knowledge and its mechanisms of control will be used to frame the analysis. Information systems is acknowledged as a discipline that is subject to frequent change. Pragmatism is used as an example to test the framework's capability of accommodating future changes in IS. Information systems scholars from three other world regions - North America, the United Kingdom and Scandinavia - have commented on the application of the framework to their own region. Research reported
\end{abstract}


in the chapters and the meta-analysis that follow in this monograph have drawn on the theoretical framework presented below.

\section{Introduction}

Information systems is a relatively new discipline in the Australian context, as is discussed in Clarke elsewhere in this monograph. Its contribution to Australia has increased with the growing understanding of the importance of computer systems in assisting organisations and individuals to achieve their goals. Given the growing contribution of the IS academic discipline to Australia, the study reported in this publication is timely, as it aims to investigate the state of IS in the universities of the region. The strategic benefits of gathering data in order to access increased power, status and resources for the IS discipline in Australia in the future are obvious. To maximise the future strategic benefits of doing so, however-particularly as this Australian study could act as a pilot for future Association for Information Systems (AIS) studies in other regions- the investigation needs to consider common questions in common ways. This chapter develops a theoretical framework to provide a common way of looking at data collected over a range of dimensions from different geographical areas in Australia. It also considers whether the framework is capable of accommodating future changes to the nature of IS.

It is tempting to view the development of IS in Australian universities as a unique case. There is, however, a body of knowledge that attempts to explain changes in fields of knowledge, including the emergence of new disciplines. An understanding of the past development of IS will help those in the discipline to better position the future of IS in Australia. Much of the literature on the development of disciplines comes from the sociology and philosophy of science and dates from the 1950s to the early 1980s. Since that period the philosophy of technology has emerged as another branch of philosophy, which includes study of the role of technology within the development of society (Gorokhov 1998). Some literature from both sources is relevant to a consideration of IS, as it is possible that many characteristics of its development arose because it was a new discipline, with involvement in technology. Therefore, the features and milestones of the development of IS might be typical of the early development of all or many disciplines and not unique. This reasoning was supported in the IS literature by Farhoomand (1992), who contended that the nature of progress in a discipline needed to be examined within a framework of the philosophy of science. The concept accords with Popper's (1959) argument that discovery needs to be directed by theory, instead of theory being derived from empirical observation. The development of IS as a discipline has been considered in several waves (Fitzgerald 2003) since its first emergence - most recently in 2006. This work has examined the origins and the future of IS. Bauman (1992:76), however, 
believed that 'only a [flawed] discipline...feels the need to justify its...exist[ence]'. Neither position, however, has been influential in Australia, where there has been little examination of the nature and development of IS.

At least two different views could be taken on the state of academic IS: an external view from outside the academic field, which includes the view of IS practitioners, and an internal one, as seen by IS academics (Hirschheim and Klein 2003). This chapter, like much of the literature, focuses largely on the internal view of IS, leaving the external view to another time, after an initial examination of the IS discipline in Australian universities has been undertaken. When taking an internal perspective, research and teaching perspectives could be considered in a discussion of the state of IS in Australian universities. Most of the literature on the state and development of IS concentrates on research issues, rather than teaching. Consequently, the review of the literature presented below regarding the state and development of IS places emphasis on research issues rather than on teaching issues.

Many people view IS as an applied science, as evidenced by the accreditation of IS programs in US business schools by ABET (formerly referred to as the Accreditation Board for Engineering and Technology) (Challa et al. 2005). Science has been described as a convention, in which the norms, expectations and values of the group while searching for understanding are relevant (Klein et al. 1991). As such, social characteristics are important to the development of science. Bunge (1979) differentiated between culture-free pure science and scientific technology, where the latter was applied in nature and involved ethics, while later writers saw science and technology as being interdependent or hybridised (Pitt 2000; Latour 2003). There has been much debate about how scientific progress comes about (Lee 1989) with many explanations put forward. The methods proposed for scientific progress include, for example, incremental verifications (the logical positivists), the increasing consensus of researchers (Polanyi 1958), the use of falsifications (Popper 1959), revolutions that overturn previous paradigms (Kuhn 1970), progressive or degenerative research programs conducted over extended periods (Lakatos 1970), political practices (Foucault 1977) or research trails versus tinkering (Chubin and Connolly 1982).

An overview of some of the literature related to scientific progress and the development of disciplines is presented in this chapter, particularly where it has been linked in the past to IS. It is believed that the literature provides a theoretical context for a study designed to characterise the state of the IS academic discipline in Australia. After an examination of the literature, a framework will be developed to guide the collection and analysis of data for the study reported elsewhere in this monograph. The framework is then examined to assess whether it is sufficiently dynamic to accommodate a more recent development in IS. 


\section{IS as a discipline or field}

There are different ways of defining a group of researchers undertaking related research. At least five definitions have been applied to IS. Keen (1991) saw nothing unique in IS research in its topics, theory or methodology, and referred to IS as a 'self-defined community' as researchers 'declare[d] themselves as members'. King (1993) viewed IS as 'not even a field', but as 'an intellectual convocation that arose from the confluence of interests among individuals from many fields'. A 'field' has been defined as

an area of knowledge and learning which is not yet accepted as a discipline. Fields of study tend to be more recent areas of scholarship with somewhat fuzzy boundaries; significant numbers of concepts within them are open to debate; and researchers and scholars in the area tend to draw heavily on old-established disciplines for their methodologies and conceptualisations. (Tardif 1989)

A discipline has sharper boundaries. Tardif (1989) saw a discipline as

a body of knowledge, definitions, and concepts built up over a long period and receiving consensus recognition by scholars; theories which interrelate the concepts and provide explanations of observed phenomena and permit predictions from them; and well established research methodologies.

Keen (1991) and King (1993) saw IS as a sub-field; Hirschheim et al. (1996) referred to IS as a field. Even more recently, little consensus has been reached on whether IS is a discipline or some other grouping. In 2002, Paul viewed IS as a 'subject seeking a body of knowledge' (p. 175). The next year, Fitzgerald (2003:225) saw IS as not 'even close to being a discipline', but as a perspective placed between technology and some other subject areas such as management. More recently, Bryant (2006) argued for reorienting the discipline of IS - as informatics.

A review of the literature suggests that researchers are still unsure about how to label IS. Many IS researchers have used the terms 'field' or 'discipline' interchangeably, avoiding the issue. Whether to label IS as a discipline, a field or as something else is likely to become clearer with greater awareness and understanding of its nature and development. Consequently, no attempt will be made in this chapter to label IS in the Australian context as a discipline or otherwise. It is more appropriate to leave this analysis until after review has been undertaken of the study findings.

\section{Approaches to the development of disciplines}

A number of different approaches have been taken to account for the nature of different disciplines and their development. A review of the literature identified that three of the approaches were largely considered independently of other 
approaches; these were theory, social processes and research methods and standards. More holistic approaches have, however, also been used to explain disciplinary nature and progress, by considering two or more of theory, social processes, research methods and standards, topics of knowledge, symbol sets for communication, the impact of local factors and the degree of professionalism. Literature that deals with theory, social processes and research methods and standards to explain the nature and development of disciplines will each be examined in turn below, followed by literature that takes a more combined approach.

\section{Largely independent approaches to explain disciplinary development}

Interestingly, some of the approaches to explain disciplinary development have waxed and waned in popularity at particular times in the past 50 years. In 1959, Popper argued that it was only through the generation of theories that scientific progress could occur. The importance of theory to a discipline has been recognised up to the present.

\section{Theory}

Kuhn (1970:182) used the word 'paradigm' in different ways, including 'universally recognised scientific achievements that for a time provide model problems and solutions to a community of practitioners'. He argued that scientific progress arose as a result of new observation or experience that necessitated a 'reconstruction of prior theory' and resulted in a paradigm shift. 'Normal science' represented the body of theory, practice and methods of inquiry that were accepted by a group of researchers, typically expounded in textbooks of the discipline. Wernick and Hall (2004) analysed the textbooks of a discipline allied to IS, software engineering, to examine the underlying belief system of authors from that discipline, to find that it was pre-paradigmatic with a common core of knowledge supplemented by competing sets of beliefs. It has been claimed by many researchers that there is limited theory in IS (for example, Grant 1991; Keen 1991; Paul 2002), while few textbooks have been published that provide an overview of the discipline. Hirschheim and Klein (2003), however, saw a 'generalisation deficit' (p. 257) in IS, rather than a lack of 'theoretical knowledge' (p. 268). Kuhn saw the presence of paradigms as a sign of maturity in a discipline, as they gave researchers a basis for choosing problems as well as guiding them in their investigation. Despite frequent discussion of Kuhn's work in articles about its development, IS has also been classified as pre-paradigmatic (Culnan 1987; Seddon 1991). Consequently, from this perspective it appears that IS might not have achieved the state of normal science - at least not by 1991 .

Kuhn's (1970) analysis of physical optics before the time of Newton is illuminative. As that discipline had "no common body of belief...each 
writer... [built] his field anew from its foundations... [and] there was no standard set of methods or of phenomena'. Kuhn saw early fact gathering that was not guided by some 'theoretical and methodological belief that permits selection, evaluation and criticism' as a 'nearly random activity'. He saw the result of undirected research as a morass of 'mere facts' that was too complex to be integrated with theory. Senior IS researchers have recognised the problem in IS for decades. For example, 'We seem to randomly generate research projects with the outcome that we have a scattering of results which presents a severe problem of pattern recognition' (Dickson et al. 1982). More recently, it has been claimed that IS is characterised by the problems it studies more than by a body of knowledge, or theories (Paul 2002). It could be that some IS research is guided more by the ease with which data can be gathered rather than by other criteria. It appears that, from Kuhn's perspective, IS could be at a very early stage in the development of a discipline.

Elias (1982) referred to the nature of theory in traditional physics as 'law-like theories' rather than 'process theories', which could be more appropriate in other sciences. The ideas regarding theory types might be interesting ones to apply to IS, even though not all researchers in the area-including Fitzgerald (2003) - would refer to the discipline as a science. The development of theory in IS has been acknowledged as difficult (Fitzgerald 1993; King 1994; Paul 2002; Fitzgerald 2003), despite a well-known proponent of the philosophy of technology, Bunge, seeing technology as 'philosophically productive' (Ihde 2004:120), with technological systems putting 'forth...philosophically significant theories' (Bunge 1979:172). Just one part of the difficulty could be that the origin of IS in technology and its past link with computer science has given those within and outside the discipline an expectation that law-like theories are appropriate for it. While the nature of IS stresses organisational issues rather than technical ones (Avison and Fitzgerald 1991; Galliers 1992; Hirschheim 1992; Fitzgerald 2003), the more recent emphasis on 'interpretivism' has not produced more general theory than the positivist approach (Hirschheim and Klein 2003). Another researcher (Zahedi 2004) has proposed a list of theories for IS, but argued for their greater consolidation. Fitzgerald (2003:226), when discussing theory in IS, distinguished between rules (or laws), evidenced guidelines and normative guidelines, where the last is 'an interpreted view of something a practitioner developer might consider doing, under appropriate circumstances, but...[that] would not necessarily lead to success'. Fitzgerald held that only the last kind of theory was possible in IS. Furthermore, the location of management information systems (MIS) in business schools in the United States and, to a degree, in Australia, also suggests that law-like theories and scientific method might not be the only, or even the most appropriate, approach for IS. So a mismatch between expectation and achievement as well as the complexity of process theories could account in part for the limited production of theory in IS. 
Regardless of what kind of theory is produced in IS, or what it is called, there is support for its development (Paul 2002; Fitzgerald 2003).

A decade after Popper referred to the role of theory in scientific progress, a very different view of the development of disciplines emerged. At that time, the role of social conditions in the production and assessment of scientific knowledge was recognised (Whitley 1984a).

\section{Social processes}

Even though Kuhn's views have been referred to in previous discussion on the contribution of theory to the development of a discipline, he is associated more with a different approach. In 1970, at a time of burgeoning science and higher education sectors in many Western nations, Kuhn published a seminal analysis of the social process of science, which is still referred to in the IS literature and elsewhere decades later (for example, Wernick and Hall 2004). Kuhn's treatise, The Structure of Scientific Revolutions, influenced the change in attitude to science and the nature of the development of disciplines. Kuhn emphasised the social mechanisms that created a scientific discipline (Ariav et al. 1987), such as conferences, journals and academic departments, which have also been referred to as 'mechanisms of control'.

Hirschheim and Klein (2003) saw the control of rewards and punishments by academics from other disciplines as driving IS research to become more theoretical and less applied. Although such pressure could increase the acceptance of IS as a discipline, Hirschheim and Klein considered that a less applied orientation reduced the relevance of IS to practitioners, and therefore its viability.

A link between knowledge and power was proposed by Foucault (1977), who also recognised the significance of social issues on the nature and development of a discipline. Foucault would see the status of IS as a political issue, rather than the achievement of ontological or epistemological positions. The supporters of this view see IS as becoming a discipline only once sufficient 'status has been conferred by institutional practices...[including] the ability to form departments, appoint chairs, organise conferences [and] edit journals' (Introna 2003), or the achievement of mechanisms of control. The nature of academic leadership is another way that social issues can impact on the direction of a discipline and its perceived status (F. Land, personal communication, 23 January 2006). It can be seen that one way to evaluate the status of IS as a discipline would be to examine whether it had the mechanisms of control normally associated with a discipline.

\section{Research methods and standards}

Other researchers have considered research methods and standards in the development of a discipline. This work has led some researchers to examine the relationship between disciplines, particularly reference disciplines. Elias (1982) 
argued that 'high-status sciences' retained their position by imposing their methods on other sciences. He considered it inappropriate for scientific method to be imposed on newly emerging sciences, particularly as it was developed for, and by, other disciplines. As the emphasis of one discipline could be on physical objects while in another discipline it could be on organisational issues, the scientific methods of some disciplines could be irrelevant to other disciplines.

Different disciplines rank more highly than others in the public and academic mind. As each has its own ideology and values that colour the knowledge it produces, Elias (1982) saw interdisciplinary collaboration as 'exceedingly difficult and almost impossible in many cases'. He argued that only low-status disciplines would take heed of interdisciplinary criticism. Moreover, Elias contended that modelling a low-status discipline on a high-status discipline or its characteristics, in an attempt to gain kudos for the field or researcher, usually failed. If this last proposition is true it could have ramifications for IS because of its close relationship with its reference disciplines. The use of theory and research approaches from reference disciplines could reduce the viability of IS as a discipline while it attempts to improve the rigour of its research. Furthermore, although it has been lamented that the IS literature is not read by those in its reference disciplines (Keen 1991), this characteristic could be a typical of any discipline.

The concept of 'restricted and unrestricted science' (Rip 1982) is relevant to an analysis of the nature of IS. In restricted sciences there is considerable control of the 'knowledge object', which allows a researcher to tightly restrict the behaviour of the object being studied, whereas in unrestricted science the reverse is true (Rip 1982). Rip argued that the high status of restricted sciences encouraged researchers from unrestricted sciences to become more like a restricted science by importing restrictedness. Signs of a restricted science include use of sophisticated instruments, standardised procedures and empirical generalisations that give increased credibility and allow research assistants or research students to undertake routine work.

There is evidence that points to IS as being unrestricted, despite technical IS research appearing more restricted. Criticism of IS research approaches indicated that many of the instruments that had been used were not sophisticated, research procedures were far from standardised (Straub and Carlson 1989; Boudreau et al. 2001) and a wide range of approaches from reference disciplines were considered appropriate (Ahituv and Neumann 1986; Culnan and Swanson 1986).

Although greater standardisation of some research procedures has been seen more recently - at a time when it has been suggested that IS is now itself a reference discipline (Baskerville and Myers 2002) - other researchers have pointed to the difficulty in reaching consensus on the most appropriate methods for IS (for example, Hirschheim and Klein 2003), and challenges associated with the 
diversity of methods in use (Frank 2006). Even though the view of the development of IS by practitioners is an external perspective, and this chapter has restricted itself to the internal view from IS academics, there will also be an internal perspective on the relevance and quality of IS teaching to future and current practitioners and other students.

Research education itself could be seen as a standardised procedure where it is specialised to a particular discipline. Relatively recent figures indicated that IS researchers in the United States had gained their highest degree across a broad range of disciplines (Walstrom et al. 1995), revealing that the research training process for IS academics trained before 1995 in that country was far from standardised. It appears that a similar diversity was found in the education of Australian IS researchers until 1996, but that this diversity has narrowed since then. An anonymous reviewer of this chapter contended that the diverse educational backgrounds of the 'fathers of the field' of IS are significant when examining the current nature of IS.

In addition to theory, social issues and research methods and standards, other approaches were identified in a review of the literature as having been proposed as contributing to an understanding of the nature and development of a discipline. These were more joint approaches, which combined two or more other approaches.

\section{Combined approaches to explain disciplinary development}

There is majority support for examining the body of knowledge along with the social processes, when considering the development of a discipline (Becher 1994), as 'we cannot...artificially separate the...substantive content from...social behaviour' (de Solla Price 1970). Becher (1987) examined the nature of three different disciplines by examining their tacit knowledge (which derived from the body of knowledge) along with their linguistic behaviour (a social process). Like Tardif (1989), Paul (2002) and Hirschheim and Klein (2003), Fitzgerald (2003) considered that a discipline required a core body of knowledge. Fitzgerald and Paul, however, saw a body of knowledge as being more than an agreed set of topics; it included the set of laws, rules or evidenced guidelines - that is, theory. Fitzgerald (2003:226) postulated that IS had 'the trappings of a discipline... [such as] mechanisms of control [which are social processes], but without the core body of knowledge or agreed theory'. Consequently, Fitzgerald viewed IS as a 'perspective' rather than a discipline.

Hirschheim and Klein (2003) saw the IS body of knowledge as incorporating some social processes and theory, when they proposed that its four components were technical, theoretical, ethical and applicative knowledge. Hirschheim and Klein saw the development of applicative knowledge, which 'required...[the application of] theoretical knowledge to specific circumstances' (p. 266), as being 
necessary to reach understanding and consensus in IS. They considered that the limited extent of applicative knowledge in IS threatened the viability of the discipline. The discourse needed to develop the body of knowledge for IS, particularly applicative knowledge, would increase communication and the relevance of IS - internally to the academic discipline and externally. In later work, Klein and Hirschheim (2006) saw IS at risk because it was made up internally of several 'communities of practice and knowing' (CoP\&K), each with different values and legitimacy criteria, and because there was limited connection from academic IS' internal CoP\&K to the outside. Discourse would, however, benefit the development of the discipline by helping to derive a common language across groups impacted on by IS, reducing the state of fragmentation in IS and overcoming its significant communication gaps (Hirschheim and Klein 2003).

Shinn (1982) considered concepts that related social processes, research procedures and theory development when he examined the intellectual and social structure of a range of disciplines, in particular looking at the intellectual division of labour. He found some disciplines to be highly formalised, with a dichotomy between the gathering and collation of findings on the one hand, and experimentation, theory and hypothesis on the other. One would expect that the more restricted a science (Rip 1982), the more formalised were its intellectual and social structures. As expected from its degree of restrictedness, IS is not as formalised in this way as are some other disciplines. Where interpretivist research is undertaken in IS, the data gathering and the theory building could be interleaved. Even in IS positivist investigations it is likely that the chief investigator/s will be involved in all stages of the process. The latter characteristic is dependent partly on the limited success of IS in attracting research funds (Ridley et al. 1998), which relates in turn to the perceived status of the discipline. Consequently, relatively few academic IS researchers have funding to employ assistants to carry out some of the research tasks.

The work of Chubin and Connolly (1982) allows further understanding of the combined pressures that have acted on the IS discipline. The authors argued that 'research trails' became institutionalised by offering potential rewards such as legitimacy and access to resources. On the other hand, 'tinkering' with new ideas or novel developments is normally opposed. Research trails are likely to use the epistemologies, research strategies, theory and perhaps even the topics of existing established research of reference disciplines. In IS, those who follow the existing research trails that were established by the reference disciplines might be more likely to be rewarded with tenure, promotion and access to research grants, as rigour is easier to demonstrate. Efforts to establish appropriate independent research approaches and traditions for IS could be seen as tinkering, as it is more difficult to claim that work is rigorous if it does not follow established traditions. Elias (1982) has, however, argued that greater independence of a discipline leads to its development and, it is assumed, eventual 
research rewards. It is possible that the path to the development of IS could involve breaking with some traditions established by the reference disciplines.

\section{Whitley's theory of scientific change}

Whitley's theory of scientific change (1984b), which viewed disciplinary development as a social process in combination with other approaches, has been applied to many disciplines, including IS (Banville and Landry 1992; Checkland and Holwell 1998). Whitley categorised some sciences as highly professionalised, with high task certainty, routinisation of activities and division of labour-a categorisation that echoed the work of Biglan (1973), Kolb (1981), Rip (1982) and Shinn (1982). Kuhn's (1970) 'normal science' fell into this category; however, other sciences were not highly professionalised, with high task uncertainty, decentralised control of work process and limited routinisation of tasks. Where a discipline was not highly professionalised, local contingencies had a high impact, such as the influence of local political pressure. Ruscio (1987) also found that local factors resulted in substantial variations among universities for the same discipline. Non-professionalised disciplines could account for Ruscio's finding.

In disciplines that are not highly professionalised, researchers investigate disparate problems that are likely to vary in nature and approach to those of concern to practitioners. Researchers work in flat non-hierarchical groups, or independently, rather than in highly structured teams with a clear division of tasks. Information systems appears to fit the mould of a discipline that is not highly professionalised. Furthermore, if local contingencies are likely to have a high impact on IS, it would be expected that considerable variation would exist in the nature of IS research between different universities and regions. There is evidence of considerable variation in the nature of IS research between nations, IS curricula and IS research education.

Whitley (1984b) suggested that three conditions needed to exist for the establishment of distinct scientific fields. These were the need for

1. scientific reputations to become socially prestigious and to 'control critical rewards'

2. the establishment of standards of research competence and skills

3. a unique symbol system to allow exclusion of outsiders and unambiguous communication between initiates within the field.

Whitley's first condition is a social process and relates to mechanisms of control. Scientific reputations are established, and critical rewards are obtained, through publication records and success at attracting research funding (Mingers and Stowell 1997. There were more IS publication outlets available in 1995 than in 1980 (Cule and Senn 1995), and many more in recent years (Hirschheim and Klein 2003). In general, these publication outlets are now administered by fellow 
IS researchers. Access to funding, however, remains tenuous while external funding decisions are made by individuals outside the discipline - as has happened with the allocation of Australian Research Council (ARC) grants (Ridley 1997) during much of the development of the IS discipline in Australia.

Whitley's second condition - the establishment of research skills (and standards) - appears to be one component of a core body of knowledge, just as in the preceding discussion it has been seen that theory is also a component of the body of knowledge. Continuing debates regarding the quality of IS research and appropriate epistemologies and methodologies (Benbasat and Weber 1996; Boudreau et al. 2001) are signs that activity is taking place regarding Whitley's second criterion for the establishment of a field, but that it has not been resolved. More recently, however, there have been some signs of increasing consensus.

Whitley's third condition - the existence of a unique symbol set-appears to be another component of a core body of knowledge. Whitley's third criterion for the establishment of a field is hard to meet as long as reference disciplines remain important to IS. Because so many reference disciplines inform IS research (Walstrom et al. 1995; Baskerville and Myers 2002) and the symbolic systems of each vary and compete, a dedicated and accepted IS symbol system has yet to emerge. The Framework of Information System Concepts (FRISCO) report that was produced in 1996 to clarify important IS definitions (Verrijn-Stuart 2001) is one demonstration of attempts to satisfy the third criterion.

Interestingly, however, two other components that were identified in earlier discussion of the literature as contributing to a discipline's body of knowledge fall outside Whitley's three conditions for the establishment of a distinct scientific field. Theory (or laws, rules and evidenced guidelines) is not included within Whitley's conditions for the development of a distinct field; nor is an agreed set of topics.

In earlier work, Whitley (1984a) conceptualised seven stable categories to classify variations in the degree of mutual dependence between researchers of a field as against variations in the degree of task uncertainty. These seven categories can be used to differentiate the nature of one discipline from another. The categories have been applied to IS by researchers for two decades.

Researcher mutual dependency was defined as dependence upon particular groups of colleagues to make competent contributions to collective intellectual goals', while task uncertainty referred to 'the extent to which work techniques are well understood and produce reliable results' (Whitley 1984a:781). Where task uncertainty is low, there is an 'established set of research techniques' that 'can be acquired through formal training programmes' where 'success is easy to determine' (Whitley 1984a:781). Of the seven categories, IS has been classified as a fragmented adhocracy (Culnan and Swanson 1986; Banville and Landry 1992; Culnan et al. 1993; Swanson and Ramiller 1993; Checkland and Holwell 
1998; Hirschheim et al. 1996; Hirschheim and Klein 2003; Kanungo 2004). Fragmented adhocracies display high task uncertainty with low researcher mutual dependence, so researchers from these disciplines make diffuse contributions to fluid goals that are contingent on local pressures (Whitley 1984a). Another characteristic of fragmented adhocracies is their openness to the general public (Whitley 1984a), as they tend not to have unique symbol sets that exclude the uninitiated. It is suggested that the characteristics of IS as a fragmented adhocracy work against it becoming a distinct scientific field.

It has been seen in a review of the literature that the establishment of theory, social processes, research methods and standards, a unique symbol set and a set of key topics have been used to explain the nature and development of disciplines in the past. A core body of knowledge appears to subsume theories, research methods and standards, the existence of a unique symbol set and a set of key topics. An examination of the relationship between the impact of local pressures and the degree of professionalism has also been used to help account for the nature of disciplines.

Although little literature was found that related teaching issues to the state of IS in universities, as an internal academic perspective must include teaching issues, any framework developed will need to be capable of encompassing this area. It is argued that for completeness, the relevance and quality of teaching need to be considered. The set of key IS topics must denote then, not only research topics but relevant teaching topics, and will be one means of achieving interaction between the internal and external perspectives of IS. Like research, teaching quality is also concerned with methods and standards.

\section{Motivation to understand the nature and development of a discipline}

The author de Solla Price $(1961,1963)$ believed it was possible to trace the history of a discipline through its artefacts, which included the number of researchers as well as the number of papers, journals and scientific societies it engendered. He referred to the difficulty of a new field in making progress, and the characteristic that large disciplines grew faster than small ones (1963). This could be because large disciplines are more able to control critical rewards and exert political power and so meet the first criterion for Whitley's establishment of scientific fields - controlling critical rewards through a range of mechanisms of control.

Taking a disciplinary perspective results in cross-fertilisation and an increased sense of unity (Becher 1994), which brings other benefits in turn. Disciplinary cultures frequently span institutional and national boundaries (Becher 1994). A social mechanism, the 'invisible college', was described by de Solla Price (1961; 1963). Culnan (1987) defined invisible colleges as the clustering of researchers 
into informal networks, 'which tend to concentrate on examining common questions in common ways'. De Solla Price (1963) saw membership of an invisible college as conferring power and status on an individual and the network. As these networks of researchers are better placed to lobby for better access to resources and funds (Ridley 1997) than individuals, individuals and researcher networks are likely to be advantaged by an increased awareness and understanding of their discipline.

The following brief examinations of two other disciplines are presented to demonstrate that it is possible to analyse disciplines from the perspective of their development and it is advantageous to do so. The reader is asked to note reference to approaches to clarify the nature and development of disciplines in the following vignettes, as identified from the review of the literature presented earlier.

\section{Vignettes of disciplinary development}

An examination of the early development of two other related disciplines could help clarify the development of IS.

\section{Management}

Whitley (1984a) tracked the development of management as a discipline. Like IS, management has been categorised as a fragmented adhocracy, but it has had a longer history. Management originated as a distinct discipline about 1960. Until the late 1950s, US business schools taught material from economics, mathematics and psychology. The distinct labour market that emerged after a critical mass of management doctorates graduated allowed the specification of a management doctorate and scholarly repute as criteria for appointment to academic positions and senior posts in management. These developments allowed management researchers to distance themselves from lay criteria and standards and increased their degree of mutual dependence. Consequentially, these changes limited their need to seek approval from non-management audiences for reputations and rewards (Whitley 1984a). It can be seen in this brief vignette that a specific doctoral qualification in management, and the achievement of a critical mass of doctoral graduates, were keys that led to the development of the management discipline.

Many management sub-disciplines experienced a need to debate the most appropriate traditions to direct their research and choice of research methods. This has been true of organisational behaviour, accounting, marketing, strategic management and policy, operations management and operations research (Klein et al. 1991). It is little surprise then that IS has not escaped similar debate. 


\section{Computer science}

Computer science is another discipline that can be used to demonstrate that the concerns of the IS community for the future of its discipline are not unique. Computer science experienced problems associated with the youth of its academics (Gries and Marsh 1988), the diverse backgrounds of its researchers (Hopcroft 1987) and a need to 'cease its largely inward-looking activities and branch outward' (Gries et al. 1989). Doubts were later expressed about the future of the discipline and fears that computer science could become irrelevant (Freeman 1995). There were calls for computer science to develop its own disciplinary characteristics and to avoid emulating high-status disciplines such as physics (Hartmanis 1995b). Other researchers in the same discipline debated the nature of computer science and tried to determine if it was a subset of engineering, science, mathematics or something more (Denning et al. 1989; Hartmanis 1995a). King (1994a) observed that the majority of computer science departments were found within engineering schools, and that very few were completely independent with the same status as other schools.

\section{An analysis of the literature to develop a framework}

After having examined IS and non-IS literature that reviewed approaches to the development of disciplines, and considered two examples from related disciplines, a method was sought to develop a framework that could be used to guide the examination - to be conducted elsewhere - of the nature and development of IS in Australian universities. Not only did the components of the framework need to be identified, along with their relationship, an evaluation was sought of whether a framework of the development of a discipline from the general literature was consistent with that developed from the IS literature. In other words, would IS and non-IS researchers share a common view of the components that contributed to the nature and development of a discipline? It was reasoned that if the perspectives of each group of researchers on the nature and development of a discipline were consistent, this would act to validate the framework derived from the literature.

\section{Methodology}

A thematic analysis process for a structured review was followed (Dixon-Woods et al. 2005), in which relevant literature identified previously was classified as having discussed one or more approaches that contributed to an understanding of disciplinary development. A data-driven approach was adopted, in which the themes emerged from the data. The analysis did not reflect the frequency of the themes, but instead accepted themes that offered a 'high level of explanatory value' (Dixon-Woods et al. 2005:47). The relationship between the identified components was also examined. As it was considered necessary to examine the views of researchers from IS and other disciplines, it was acknowledged that 
any classification of approaches to disciplinary development derived from the literature was unlikely to be complete, due to the quantity of publications available on the topic. It is argued, however, that only sufficient analysis is needed to identify the main issues when reviewing disciplinary development, until theoretical saturation is achieved, as is done when working towards concept development in primary qualitative research (Dixon-Woods et al. 2005). Therefore any omission of literature in the area is unlikely to weaken the analysis and classification process. The purpose of distinguishing the themes identified from the IS literature from those of the wider literature was to allow an evaluation of the degree of consistency between IS researchers and those from other disciplines. If the framework developed matched the components identified from both groups of literature, and the relationship among the components, the robustness of the framework would be strengthened.

As classification is a largely subjective process, two trained IS researchers categorised the literature independently. Discussion took place where the classification differed, until agreement was reached. The major themes derived from the literature, social processes and a core body of knowledge, were used for analysis. As foreshadowed, the latter category was broken down into four subgroups: research and teaching methods and standards (or IS knowledge gain and transfer), a unique symbol set, key research and teaching topics (or IS knowledge domain) and theoretical issues. To acknowledge the importance to IS of providing professional training, any literature that considered teaching methods and quality in the development of the discipline was grouped with the research and teaching methods and standards category, while literature on teaching relevance was grouped with key research and teaching topics. The impact of local influences was also sought.

A record was made for each reference to these themes, by author. The results were delineated further by whether the author came from the IS discipline or elsewhere, as determined by the publication outlet. The relationship between the themes was captured by recording the combination of issues discussed with reference to disciplinary development, for each author.

\section{Results}

Table 3.1 sets out the results of the analysis of the literature, where the components explicitly examined in discussion of the nature and development of disciplines were identified and then classified. Themes taken from a review of the IS literature have been distinguished from those that were derived from the more general literature. The order of listing in the table matches that followed in the earlier discussion. 
Table 3.1 Identification from the literature of framework components for disciplinary development

\begin{tabular}{|c|c|c|c|c|c|c|}
\hline \multirow[b]{2}{*}{ Published research } & \multirow[b]{2}{*}{$\begin{array}{l}\text { Social } \\
\text { processes }\end{array}$} & \multicolumn{5}{|c|}{ Core body of knowledge } \\
\hline & & \begin{tabular}{|l|} 
Research \& \\
teaching \\
methods \& \\
standards
\end{tabular} & $\begin{array}{l}\text { Unique } \\
\text { symbol set for } \\
\text { communication }\end{array}$ & \begin{tabular}{|l|} 
Research \& \\
teaching \\
key topics
\end{tabular} & \begin{tabular}{|l|} 
Theoretical \\
issues
\end{tabular} & $\begin{array}{l}\text { Local } \\
\text { influences }\end{array}$ \\
\hline Popper (1959) & & & & & 0 & \\
\hline Klein et al. (1991) & $\bullet$ & & & & & \\
\hline Bunge (1971) & 0 & & & & & \\
\hline Foucault (1977) & 0 & & & & & \\
\hline Keen (1991) & $\bullet$ & & & & & \\
\hline Paul (2002) & & & & $\bullet$ & $\bullet$ & \\
\hline Wernick and Hall (2004) & 0 & & & 0 & & \\
\hline Kuhn (1970) & 0 & 0 & & & 0 & \\
\hline Elias (1982) & & 0 & & 0 & 0 & \\
\hline Becher (1994) & 0 & & & 0 & & \\
\hline Hirschheim and Klein (2003) & $\bullet$ & & $\bullet$ & & $\bullet$ & \\
\hline $\begin{array}{l}\text { de Sola Price }(1961,1963, \\
1970)\end{array}$ & 0 & & & 0 & & \\
\hline Tardif (1989) & & & & 0 & & \\
\hline Fitzgerald (2003) & $\bullet$ & & & $\bullet$ & $\bullet$ & \\
\hline Rip (1982) & & 0 & & 0 & & \\
\hline Shinn (1982) & 0 & 0 & & & 0 & \\
\hline Ridley et al. (1998) & $\bullet$ & $\bullet$ & & & & \\
\hline Chubin and Connolly (1982) & 0 & 0 & & 0 & 0 & \\
\hline Banville and Landry (1992) & $\bullet$ & & & & & $\bullet$ \\
\hline Checkland and Holwell (1998) & $\bullet$ & & & & & $\bullet$ \\
\hline Biglan (1973) & & & & 0 & & \\
\hline Kolb (1981) & & 0 & & & & \\
\hline Whitley (1984b) & 0 & 0 & 0 & & & 0 \\
\hline Ruscio (1987) & & & & & & 0 \\
\hline Cule and Senn (1995) & $\bullet$ & & & & & \\
\hline Mingers and Stowell (1997) & $\bullet$ & & & & & \\
\hline Verrijn-Stuart (2001) & & & $\bullet$ & & & \\
\hline Culnan and Swanson (1986) & $\bullet$ & & & & & $\bullet$ \\
\hline Culnan et al. (1993) & $\bullet$ & & & & & $\bullet$ \\
\hline Swanson and Ramiller (1993) & $\bullet$ & & & & & $\bullet$ \\
\hline Kanungo (2004) & $\bullet$ & & & & & $\bullet$ \\
\hline Culnan (1987) & $\bullet$ & $\bullet$ & & & & \\
\hline
\end{tabular}

- derived from IS literature

o derived from non-IS literature 


\section{Discussion and findings}

As all the categories were found in the IS and the general literature, this finding was interpreted to mean that both groups shared a common view of the components used for explaining the nature and development of a discipline. Consequently, it was assumed that the components identified were robust and appropriate for inclusion in a framework of the development of a discipline. From the number of studies examined, and the results, it was assumed that saturation of topics had been reached. As many authors identified more than one component, a combination of components was considered most appropriate to account for the nature and development of the IS discipline.

\section{Framework development}

A framework to account for the nature and development of a discipline was prepared, using the components and their relationships identified in the review and analysis of the literature. Whitley's theory of scientific change and related concepts influenced the development of the theoretical framework. The framework has been used to consider the historical and present position of IS in Australian universities, in combination with a 'body of knowledge', using Fitzgerald's understanding of the term. The two constructs from Whitley discussed below were utilised in the framework.

The first construct that sets out Whitley's three conditions for the establishment of a distinct scientific field has been used in part for the theoretical framework. As set out earlier, these are: a) scientific reputations to become socially prestigious and to 'control critical rewards'; b) establishing standards of research competence and skills; and c) a unique symbol system to allow exclusion of outsiders and unambiguous communication between initiates within the field.

As outlined earlier, the first condition from Whitley is a collection of mechanisms of control, or social processes, while the second and third conditions relate in part to a core body of knowledge. Whitley's second and third conditions, however, were found insufficient to cover all aspects of a discipline's body of knowledge. For example, the second condition excluded teaching issues, even though IS academic teaching is largely the means by which an understanding of the discipline is imparted to future academics and practitioners. As demonstrated in the analysis of the literature, the 'laws, rules or evidenced guidelines' component of 'body of knowledge' (Fitzgerald 2003; Paul 2002), which has not been incorporated into the first construct above, also needs to be considered when examining progress towards the development of IS in Australia. Furthermore, key topics were also shown by analysis to be an essential component of the body of knowledge, and included relevant research and teaching topics. The second construct concerns the degree of professionalisation of the discipline, which is expected to decrease as the impact of local contingencies increases. 
Consequently, a two-part framework was developed as a result of the literature analysis that includes mechanisms of control for the discipline and the core body of knowledge, or knowledge base - both considered against time. The framework has been used to guide some of the regional data collection and analysis for the Australian study. The second condition from Whitley was adapted and incorporated into the core body of knowledge, as research and teaching methods and standards (or knowledge gain plus knowledge transfer), while the third condition was included as the unique symbol set. Two additional components, laws, rules and evidenced guidelines (or knowledge types), and research and teaching key topics (or IS knowledge domain), have also been included in the framework. Figure 3.1 illustrates the first part of the framework used for the study and sets out the components that characterise the nature and development of a discipline. The second part of the framework is set out in Figure 3.2, which shows the inverse relationship between the impact of local contingencies on the IS discipline and the degree of professionalism.

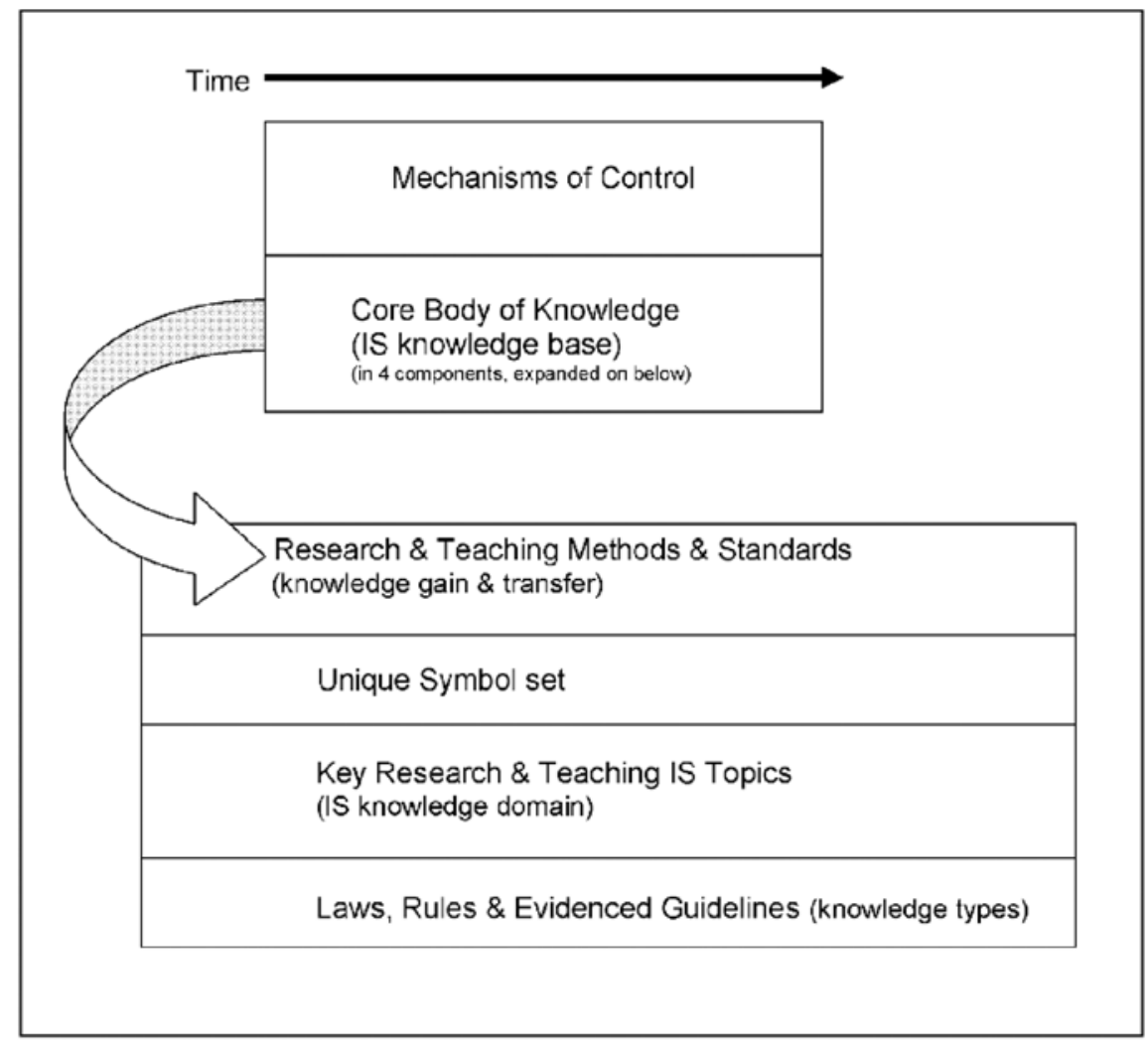

Figure 3.1 Framework for study: components of academic discipline 


\section{Impact of Local Contingencies}

Degree of Professionalism

Figure 3.2 Framework for study: inverse relationship between impact of local contingencies on IS discipline and degree of professionalism

\section{Adaptability of framework to future change in IS}

Frequent and continuing change in the IS discipline has been well recognised and described frequently. For example, the major role of institutions that teach IS has been described as preparing graduates for an environment that changes continuously (Al-Imamy and Farhat 2005). Moreover, Kanellis and Paul (2005) remind the reader of a number of well-known IS researchers who have stressed that flexibility is a success variable for IS.

It follows then that the theoretical framework proposed to characterise IS in Australia will need to adjust to such change, or be modified on a continuing basis. An example of possible changes associated with each component of the framework is provided in Table 3.2, to illustrate the continuing pressures on the framework.

It is argued that the framework needs to be able to accommodate future developments in IS within one or more of the components listed in Table 3.2 without adaptation, if it is to be of value. A static framework will quickly become superseded, given the rate of change in the discipline. Therefore, a further way of validating the utility of the framework is to test whether it is dynamic enough to accommodate a new development in IS.

A number of topics have become influential in IS research or teaching in recent years, including design science and pragmatism. The design science paradigm places focus on the design, building and application of new artefacts for computing and communication (Hevner et al. 2004; Ramesh and Rao 2005), and has been linked to pragmatism. As an example of a new development in IS, the relatively recent interest in pragmatism in IS is examined below, after a review of the literature on this topic. The framework was then assessed to see whether it was possible to accommodate pragmatism in it without adaptation of the 
framework. If accommodation is possible, the process undertaken will be regarded as further demonstration of the robustness of the framework. If the framework needs adaptation in order to accommodate the example of change to the nature of IS, this finding will be regarded as a demonstration that the framework needs additional refinement.

Table 3.2 Example of possible change for each component of the framework

\begin{tabular}{|c|c|c|}
\hline Level 1 component & Level 2 component & Example of change \\
\hline Mechanisms of control & & $\begin{array}{l}\text { Introduction of new publication outlets for IS; } \\
\text { change to the administrative placement of IS } \\
\text { schools in Australian universities with changing } \\
\text { enrolments }\end{array}$ \\
\hline \multicolumn{3}{|l|}{ Core body of knowledge } \\
\hline & $\begin{array}{l}\text { Research and teaching } \\
\text { methods and standards }\end{array}$ & $\begin{array}{l}\text { Introduction of new methods of IS research or } \\
\text { teaching, or standards, such as standardised } \\
\text { use of Vista for teaching or the introduction } \\
\text { of e-print repositories in universities }\end{array}$ \\
\hline & Unique symbol set & $\begin{array}{l}\text { Reaching agreement on a unique symbol set } \\
\text { for the IS community }\end{array}$ \\
\hline & $\begin{array}{l}\text { Key research and teaching IS } \\
\text { topics }\end{array}$ & $\begin{array}{l}\text { Introduction of new IS topics for research or } \\
\text { teaching, such as pragmatism and design } \\
\text { science for research, or information technology } \\
\text { (IT) control frameworks for teaching }\end{array}$ \\
\hline & $\begin{array}{l}\text { Laws, rules and evidenced } \\
\text { guidelines }\end{array}$ & Development of new theory and its publication \\
\hline Impact of local contingencies & & $\begin{array}{l}\text { Local contingencies impacting on the degree } \\
\text { of professionalism, such as recent IS staffing } \\
\text { retrenchments in universities reducing the } \\
\text { degree of specialisation in collaborative } \\
\text { research teams }\end{array}$ \\
\hline Degree of professionalism & & $\begin{array}{l}\text { Linked through an inverse relationship; see } \\
\text { above }\end{array}$ \\
\hline
\end{tabular}

\section{Review of the recent literature on pragmatism}

Classical pragmatism is a philosophy developed and popularised by the American philosophers Peirce, James and Dewey about the beginning of the twentieth century (Sundin and Johannisson 2005). Although the word 'pragmatic' is used by laypeople to indicate a concern with the practical outcomes of actions, the philosophy of pragmatism holds that theory needs to contribute to practice or experience, while utility can be used to test truth. The earlier classical pragmatism is distinguished from the more recent neo-pragmatism because the former places emphasis on the experience, while the latter focuses more on the role of language than the experience (Rorty 1999; Sundin and Johannisson 2005).

The term pragmatism has been used numerous times in the IS and related literature, where it is used most often in the lay sense (as a notable example by three Australian authors; see Darke et al. 1998). Particularly since 2003, however, in this same literature, pragmatism has also been used to mean 'a deep seated chosen philosophical stance rather than an approach to one-off events' (Martin 2004:28). Pragmatism is used often in conjunction with reference to action research and/or critical realism (as an example see Hjorland 2005). Mingers (2002:296) saw pragmatism as a 'view about the purpose of science...[as] it is 
essentially a practical activity aimed at producing useful knowledge rather than understanding the true nature of the world'. Put another way, in pragmatism, practical and political consequences were sought from research, not a contribution to 'foundational knowledge' (Brannick and Coghlan 2006:15).

That there is a connection between action research, critical realism and pragmatism is obvious, given that all three aim to bring about some change to a situation. Baskerville and Myers (2004) saw a more fundamental link between action research and pragmatism. They suggest that pragmatism is the philosophy that underpins most action research, as the following four pragmatist premises also underlie action research.

1. Establish the purpose of any action.

2. Practical action needs to be taken in response to the problem.

3. Practical action must inform theory.

4. The reasoning and the action need to be situated socially.

As there has been strong interest in action research (Baskerville and Myers 2004) and critical realism (Wikgren 2005) in recent years, it is not surprising that reference to pragmatism as a philosophy relevant to IS and its reference disciplines has also been noted recently. Is it possible, however, to incorporate this latter recent development into the framework for IS without modifying it?

\section{Testing the placement of pragmatism in the framework}

From the review above, it can be seen that pragmatism falls within the core body of knowledge component of the framework. Depending on how it is used, pragmatism can be classified within two of the sub-components of this core. Pragmatism can be regarded as a research and teaching method and standard, in a similar way that action research and critical realism are regarded as methods for undertaking research. When viewed as a topic on which research can be undertaken, however, pragmatism can also be considered a key research and teaching IS topic, just as action research is the topic of many research papers, including those invited by Baskerville and Myers (2004).

It can be seen that no changes need to be made to the framework to accommodate the recent interest in pragmatism. Although this finding suggests that the framework is robust, further testing will be needed by examining whether other new IS developments can be placed in the framework without its modification.

\section{Applicability of the framework to IS in other world regions}

As the framework components were derived and validated from literature that originated largely outside Australia, it seems reasonable to consider whether the framework can be applied to IS in world regions beyond Australia. It is premature to test the framework using data collected from IS in other world regions until it has been tested with data gathered in Australia, as modifications to the 
framework might be necessary. Examining the framework using data collected within Australia will be reported on elsewhere in this volume; however, the next section reports on a preliminary examination of the applicability of the framework to IS in world regions outside Australia, using the broad experiences of internationally known IS scholars from those regions.

Expert IS scholars from North America, the United Kingdom and Scandinavia were approached and were asked to comment briefly on the relevance of the framework to IS in their own region. The three international regions were chosen as they were viewed as being distinctive in their contribution, while also having had a major input to the development of IS. The framework chapter was sent to the international researchers, who read it before writing a commentary on the applicability of the framework to IS in their own region. The commentaries were broad ranging, and used the framework components to guide their discussion to a varying degree. Each of the commentaries is presented below, while a later subsection collates the views of the international commentators on the applicability of the framework to the three regions outside Australia. The contributions of professors Bob Zmud (giving a North American perspective), Frank Land and Antony Bryant (giving a perspective from the United Kingdom) and Karlheinz Kautz (giving a Scandinavian perspective) are acknowledged with gratitude.

\section{Applying the framework to IS in North America: a comment from Professor Bob Zmud, from the Price College of Business at the University of Oklahoma, USA}

It certainly is a fruitful exercise to apply (and, in doing so, assess) the proposed framework. The disciplinary status of the North American IS discipline has been a topic of great interest, as reflected in my article on the discipline's 'identity crisis' (Benbasat and Zmud 2003) and the ensuing reaction to this article (King and Lyytinen 2006).

It is perhaps most important to begin by recognising the progress that has occurred in developing the North American IS discipline in the past four decades. When I completed my doctoral studies in business administration (combining organisation theory with computer science) at the University of Arizona in 1974, there were few IS faculty members in North America and, at most, two or three freshly started IS doctoral programs. In North America today, IS faculty members are well represented at the majority of comprehensive universities and colleges, in schools of business, information science and technology. As my own experiences have been solely with schools of business, I will limit the ensuing discussion to this context. This is important to note as an essay written from the perspective of schools of information science and technology would be somewhat different, though the overall message would likely be quite similar. This is a nice example of the framework's 'impact of local contingencies' component. 
The framework has four level-one components: mechanisms of control; core body of knowledge; impact of local contingencies; and degree of professionalism. This essay will unfold with my perspective of the North American experience with each of these. Concluding comments will then be provided on the usefulness of the framework in carrying out this exercise.

\section{Mechanisms of control}

The IS discipline in North America has developed quite well-in fact, surprisingly so given the relatively short time since the discipline's emergence - with regard to mechanisms of control and especially with regard to research. Mechanisms of control reflect the mechanisms put in place to facilitate the development, communication and regulation of research programs and the development, delivery and regulation of education programs and curricula.

The North American IS research community has achieved considerable success. The major conference, the International Conference on Information Systems (ICIS), is very successful and is recognised as a premier research conference. The major journals (MIS Quarterly and Information Systems Research) have achieved high Social Sciences Citation Index (SSCI) impact ratings, are respected by business school promotion and tenure committees and by institutions (Business Week, Financial Times) rating MBA programs, and are being cited increasingly by articles published in non-IS scholarly journals. In addition, a number of successful IS scholars are members of non-IS editorial boards.

The North American teaching community has also achieved success, though neither as consistent nor as substantial as observed with research. Information systems undergraduate and graduate degree programs are found in the majority of comprehensive universities and colleges, with a majority of business degree programs maintaining IS core requirements. While enrolments have gone up and down and up again in the past decade, this largely reflects the variability that characterises high-technology markets. Many universities and colleges have institutionalised IS faculties into their departmental structures; however, the control mechanism of accreditation processes has not shown much development. The widely adopted Association to Advance Collegiate Schools of Business (AACSB) accreditation process pays, at best, modest attention to IS.

\section{Core body of knowledge}

The IS discipline in North America remains surprisingly underdeveloped regarding its core body of knowledge. Essentially, a discipline's core body of knowledge reflects the consensually agreed-on research topics, research methods and teaching topics that distinguish it from other disciplines. While consensual agreement is likely to exist around a very limited core of topics regarding research and teaching, much debate continues to arise as one pushes beyond this very limited core. The focus of research programs therefore varies widely as does the 
content of IS courses and IS curricula. Still, three trends can be observed. First, over time, these 'limited cores' have been expanding, though slowly. Second, in terms of teaching, greater consistency does exist at the undergraduate level than at the graduate level. Third, regarding research methods, the North American IS discipline is increasingly receptive to the view that any research method is appropriate given that it fits with the research question(s) asked and is executed and interpreted well.

\section{Local contingencies}

Local contingencies are useful in understanding the developmental differences discussed above regarding mechanisms of control and the core body of knowledge. Again, the local context described is that situated within North American schools of business.

During the 1970s and 1980s, IS faculties in North American business schools tended to be associated with one or more of a limited number of scholarly societies: Operations Research Society of America/The Institute of Management Sciences (ORSA/TIMS; now the Institute for Operations Research and Management Sciences, INFORMS), the American Institute for Decision Sciences (AIDS; now the Decision Sciences Institute, DSI) and the Academy of Management. Each of these societies had strong research cultures and scholarly journals reflected the prevailing values and norms of faculty members across business disciplines. These values and norms were thus ingrained within IS faculties and institutionalised in the discipline's conferences, journals and doctoral programs.

No such institutional structures, however, existed regarding teaching IS in schools of business. This lack of institutional structures was exacerbated by the varied training (economics, management science, computer science, organisation theory and so on) of the faculties, the lack of pedagogical role models within local institutions and a strong bias towards research (rather than teaching) within the North American IS discipline's conferences and journals.

\section{Degree of professionalism}

Recognising the applied nature of the IS discipline and the need to align itself with prevailing school of business values and norms, the North American IS discipline has strived (with varied success) to balance the objectives of being rigorous - that is, developing and communicating new knowledge within academic communities - and being relevant - that is, developing and communicating knowledge that is actionable immediately by practice communities (Benbasat and Zmud 1999). While local contingencies (for example, local institutional values and norms, association with practice communities) are again key to explaining situational differences, the North American IS discipline 
has generally exhibited a bias that has and continues to favour rigour ahead of relevance - a bias held, generally, by North American schools of business.

\section{Summary statement}

While it is always dangerous to over-generalise, the framework does appear (at least at this very high level of analysis) useful in understanding the evolution and current state of the North American IS discipline.

\section{Applying the framework to IS in the United Kingdom: a comment from Professors Frank Land, from the London School of Economics, and Antony Bryant, from the School of Information Management at Leeds Metropolitan University, UK}

Gail Ridley has written a paper offering a framework for 'developing and evaluating the IS discipline in Australia'. This is a laudable undertaking, but it immediately raises the question: 'Why does the IS discipline need to be evaluated and developed?' And what is specific to the Australian context?

At first reading, one of the specific features of the Australian context is that IS appears to be thriving. At least there is no indication of any crisis - unlike the situation in the United States and most of Europe, where there is a steep and continuing decline in student numbers, a continuing threat to IS departments and university posts, and also to funding for teaching and research. ${ }^{1}$ We suspect that it is unlikely that Australian IS is bucking the trend, and if the decline has not yet started, it will soon do so. This might appear to undermine the effort of developing a framework, yet we would argue that it might make it even more pertinent and important. First, however, a few provisos are in order with regard to the paper itself.

Much of the first part of the paper is concerned with the extent to which IS can be regarded as a discipline, yet the title and the bulk of the paper beyond the opening section assume that it is. This evades some key issues that have been raised elsewhere (see for instance Bryant 2006) and even some of those addressed in the opening section of the paper; but since the main focus is on the framework this is, perhaps, understandable.

As it is presented, the framework falls between offering a descriptive account of the current situation in Australian IS and a prescriptive one advocating what IS should be or should become. It might then serve as a useful basis for these considerations elsewhere in the world. On the other hand, many of the issues raised are already fairly well known outside Australia.

\footnotetext{
${ }^{1}$ Other chapters in this volume, in particular the state case studies, consider this issue.
} 
Whether or not IS constitutes a discipline, it is evident that its status and role within the twenty-first century university is changing. Rather than seeking to fight some rearguard action to preserve whatever might make up the 'home turf' or territory of IS, it is far more important to raise awareness of the key issues around which IS-type activities - teaching, research and so on-gather. Some indication of these is given in the framework - for example, teaching, methods, theories and links to other disciplines. The next step might then be to offer some indication of the ways in which these foundations might be built on, within a recognised IS discipline and in cases and contexts where IS becomes (re)absorbed into one or other of its reference or kin disciplines - for example, business, management, computing and so on.

The paper in which the framework is presented discusses the issue of pragmatism - correctly distinguishing between the more common meaning of the term, in which something is pragmatic if it is of more-or-less immediate practical use and application, and the term used to evoke the work of American philosophers such as Peirce, Dewey and James, whereby concerns for truth and validity are seen against a background of practice and experience as well as against theories and concepts. Pragmatism is located within the framework in two respects; however, it is perhaps worth considering the framework as a whole from a pragmatic point of view. Does the core of the framework find any validity and authority among IS practitioners? Those involved in academic IS might spend a considerable amount of time agonising about disciplinary status, core concerns, reference disciplines and the like, but these are probably not even of passing interest to those working outside such narrow confines. Recent work in Germany on Wirtschaftsinformatik (WI) indicates that a practice-oriented discipline, gaining much of its findings and credibility from the commercial sector, continues to thrive. So a useful test of any framework might be its ability not only to capture this state of affairs, but to indicate how it might be applied elsewhere as well as be used in future developments. Ironically, reports on the current state of WI also suggest that in an effort to gain some international academic credibility WI academics are trying to mimic academic IS using the American-oriented approach, whereas precisely the inverse relationship appears to be the sounder strategy.

We offer the following example as an instance of the context that any framework or similar explanatory and exploratory project must seek to address. If we seek to understand the issues around Customer Relationship Management (CRM), our study will be concerned with the design of such a system, drawing on marketing theory and practice as well as systems theory and perhaps computer science and database theory. These 'outside' theories are not reference theories but part of our apparatus for the study. Moreover, if our study is intended to establish how effective a given CRM system has been, we will have to use different methods of analysis and draw on different theories to help in the explanation. These could 
include theories relating to the management of change and explanations of resistance to change. Further, they might have to link with theories of ethical behaviour.

There is another issue that arises from a consideration of the framework: the extent to which it focuses attention on the boundary between what is included within IS and what is excluded. In recent years, there have been various attempts to produce statements to this effect, and all have fallen foul of the complex interdisciplinary nature of IS itself. For instance, there would need to be some way in which attention was directed to topics such as computer games, including activities such as online casinos; also the impact of the market for online pornography on the development of information and communications technology (ICT). There is no evading the issue that many of the key technical developments in the 1980s and 1990s were clearly pushed through by the demand for sites with quickly loading graphics and secure online payment facilities - that is, porn sites. Similar advances have been achieved with gaming and gambling in mind. A host of antisocial applications ranging from pornography to spam and viruses to computer crime need to be seen as innovative and hugely successful application areas for IS, as well as features to be researched and overcome.

A framework must therefore include the capability of characterising the wide and complex nature of the phenomena that are being studied. Because the IS domain is undergoing constant change, as the paper notes - for example, the introduction of the phenomenon of mobile computing - what is in the framework under the heading 'nature of the phenomenon' is constantly changing. It could be that in such a friable context attempts to develop a framework are doomed from the start; on the other hand, a case might be made that in such circumstances it is imperative that some form of guidance and prescription is articulated. Perhaps the framework on offer here might serve as a useful starting point in such an endeavour.

Currently in the United Kingdom, IS departments are having to respond to considerable upheaval and change: the higher education sector is undergoing major transformation as a whole, and the number of students seeking IS-type courses, particularly at undergraduate level, is falling. On the other hand, demand for IS skills is likely to increase, but in combination with a range of other skills - technical, social and business oriented. In such an uncertain context, attempts to clarify key IS aims and characteristics are all the more critical.

\section{Applying the framework to IS in Scandinavia: a comment from Professor Karlheinz Kautz, from the Copenhagen Business School, Denmark}

Based on an intensive literature study, Ridley (2006) has developed a framework to characterise IS in Australia. Ridley considers whether related research 
undertaken by a group of researchers can be regarded as a discipline or a field. She has done so to support efforts that aim to determine whether IS is a scientific discipline. Such efforts are of course driven by the perceived need of some IS researchers to legitimise what they are doing, particularly in environments where such researchers are a minority grouping in university departments or schools and are permanently challenged by colleagues from other fields. Ridley's framework consists largely of four components, which she puts forward to characterise Australian IS: mechanisms of control, a core body of knowledge, the impact of local contingencies and the degree of professionalism. The question arises whether the framework can also be used in, and for, other geographical regions.

My comments are provided from a Scandinavian perspective. In Scandinavia, discussion about IS as a discipline has never really been dominant. Instead, there has been discussion about whether there is a unique Scandinavian approach to IS research. Scandinavian researchers settle comfortably with Lee's (2001) assessment that 'research in the information systems field examines more than just the technological system, or just the social system, or even the two side by side; in addition, it investigates the phenomena that emerge when the two interact'.

Ridley sees social processes as operating through conferences, journals and academic departments; these have also been referred to as mechanisms of control. The social process is important for the Scandinavian IS community, where numerous academic institutions have independent IS departments. These are rarely called 'department of information systems'. Although they operate under the name of informatics, information-processing science or information science, the majority of members of such departments feel like IS researchers and the different names might just be a matter of language, as all departments of course have names in the respective language of the country. The sense of community developed since as early as the late 1970s, while in 1978 the Information Systems Research Seminar in Scandinavia (IRIS) was founded. This working conference has been a meeting place for senior and junior researchers for nearly 30 years. The Scandinavian Journal of Information Systems (SJIS) has operated since 1989 and was started originally to give Scandinavian IS researchers their own voice.

Ridley's second IS component, core body of knowledge, in which she distinguishes between research and teaching methods and standards, a unique symbol set, key research and teaching of IS topics, theory/laws, and rules and evidenced guidelines, can be discussed from a Scandinavian perspective and its strong commitment to the social process.

Historically, IS research in Scandinavia took its starting point in IS development as opposed to computer science and software engineering research. Being embedded in formerly social democratic countries, Scandinavian IS research 
traditions emphasise engagement with practice. Like the editorial policy of the SJIS, however, Scandinavian IS values and welcomes theoretical and methodological pluralism. Although Scandinavian research seems to favour qualitative, interpretive or even action-based research, quantitative research of high quality can also be found. Early on, Bansler (1989) had already identified three Scandinavian IS research schools: a systems theoretical tradition, a socio-technical tradition and a critical tradition. The question arises whether such pluralism should be considered as a coherent whole or as a set of scattered methods and standards (or symbol sets). If the former is the case, IS in Scandinavia might be considered a discipline or research field, while if the latter is the case, it might not. The answers to these questions will help decide whether these elements of Ridley's framework make sense.

The key research topics in Scandinavian IS can also be examined. The SJIS-I am again citing its 2007 editorial policy statement - invites contributions on electronic commerce, IT diffusion, mobile and ubiquitous computing, organisational and societal issues, research approaches and methods and systems development methods, but explicitly states that the journal's topics are not restricted to these. Consequently, the journal has published work on other topics as well. Interesting research themes, fads and fashions come and go, but as long as IS development and use (as broad as they are) are accepted as the underlying key topics, Scandinavian IS fulfils this criterion for being a discipline. This is, of course, as long as the criterion itself can be used in such an expansive way.

Research in a discipline should certainly contribute to the body of knowledge about a phenomenon. Theories, laws, rules or evidenced guidelines also clearly contribute to a discipline. In Scandinavia, practical relevance has always had an important role in legitimate research. There is no one such 'theory of IS' or 'theory of IS development' or 'theory of IS use', and it is debatable whether there is a commonly accepted set of laws, rules and guidelines in IS. Information systems research has provided insights, guidelines and rules, often through the use of theories from reference disciplines. Even if these activities do not define theories in their own right, they at least contribute to theory building.

Finally, Ridley proposes that local contingencies and professionalism help characterise the IS discipline in Australia, and even influence each other. It is true that local contingencies and professionalism have an influence on the local manifestation of the IS discipline, but it is debatable whether they can be used to characterise the IS discipline itself. Whether the concept of locality should be considered in an examination of the nature of the IS discipline is questionable. Even if there is 'one' IS discipline in Scandinavia, with local differences from country to country, and even from university to university, this is also the case in other disciplines where there is no debate about their existence. 
Overall, IS in Scandinavia - as is explained above - is influenced heavily by its social democratic heritage and its preference for relevance. Both factors have had an influence on the degree of professionalism in Scandinavian IS research, in the sense that the term 'professionalism' is used in the framework. The outcome has been that more qualitative, interpretive and action-oriented approaches have been favoured in Scandinavian IS until recently, with less emphasis on the rigour and generalisability of the results.

Do the differences discussed above regarding IS in Scandinavia mean that IS in that region can be characterised differently to the IS discipline in, for instance, Australia or North America? Although local contingencies might influence local incarnations of a discipline, they do not necessarily challenge the general definition of the IS discipline. Thus, if in general Scandinavian IS is the same as Australian IS, the elements of a framework to characterise the nature of the IS discipline in Australia have to be used with some caution.

\section{Collating international views on the framework}

This section reviews the experiences of the four international IS scholars in applying the framework to IS in their own region, drawing on their own expertise. Bob Zmud stepped through the four top-level components of the framework before concluding that, at least at a high level of analysis, it appeared useful 'in understanding the evolution and current state of the North American IS discipline'.

Tony Bryant and Frank Land from the United Kingdom questioned why the endeavour to characterise the IS discipline needed to be done for an Australian context. Consequently, their commentary focused on global issues, pointing to the need for IS to respond to pressures to change. These included the decline in student numbers and its impact on IS teaching and research, the status, role and structural location of IS, the connection with IS practitioners, the need for IS work to integrate with theory and practice from elsewhere and difficulties associated with the increasingly fluid nature of the boundaries of IS. Bryant and Land therefore considered that a framework of the nature of the IS discipline must be capable of 'characterising the wide and complex nature of the phenomena being studied' and, in particular, accommodating change, and they referred to aspects of the framework that noted some of these issues. While supporting the need for a framework to clarify key aims and characteristics for IS, the authors' commentary also laid down some of the challenges of doing so.

Karlheinz Kautz considered how to apply the framework to a Scandinavian perspective, after pointing out that there had been more interest in evaluating whether there was a unique approach to Scandinavian IS research than considering the state of IS as a discipline in that region. Like Zmud, Kautz was able to use the four top-level framework components to review the nature of IS 
in Scandinavia; however, while being able to identify what appeared to be distinctive characteristics of IS in Scandinavia, Kautz questioned whether it was relevant to consider 'local incarnations' when attempting to characterise the nature of the IS discipline.

It can be seen then that three of the four international scholars query the purpose of characterising the nature of IS in Australia, implying that global influences on the discipline will be more important than regional ones. In two of the international regions, the framework components appeared useful to review the nature of the IS discipline in those areas. These two perspectives suggest that the framework has some value in characterising the IS discipline outside Australia and/or it should be capable of doing so. Neither position is surprising, given the development of the framework from the international literature. After the framework has been tested on a range of case studies set in Australian 'states' and reported on elsewhere in this volume - then modified where necessary - it will be interesting to test the refined framework against international settings, using broader data gathered in those settings. Future iterations of the framework might need to accommodate the requirements suggested by the international scholars who commented above.

\section{Conclusions}

A body of literature exists that examines the theory of the development of disciplines. This literature suggests that the development of IS in Australian universities should not be viewed as a unique case, but instead a range of pressures need to be considered, which act on the discipline. A brief overview of the early development of the management and computer science disciplines was presented to illustrate the development of two disciplines related to IS. Although some reference has been made in IS to theory on the nature and development of disciplines, very little use of the material has been made to provide a context within which to view the past and present nature and position of IS in Australian universities.

The project reported on elsewhere in this monograph gathered data across a range of dimensions for universities in each large region in Australia. It has been argued that if such data collection is to be utilised in a strategic way to increase access to resources for the IS discipline, it will be necessary to integrate the data and findings from regions across the dimensions, so that the relationships within, between and among the regions and dimensions can be analysed, and the contributing factors better understood. A theoretical framework to guide data collection and analysis was developed from an analysis of the IS and non-IS literature on the development of disciplines and presented in this chapter. As the framework's components could be derived independently from the IS and non-IS literature, this characteristic strengthened the validity of the framework. The framework will integrate different aspects of the broader study and provide 
a common way of looking at data collected over a range of dimensions from a range of regions and Australian universities.

Data gathered from universities in the regions around Australia can be used to assess the extent to which mechanisms of control have been established in Australian IS, along with the four components of the body of knowledge (research and teaching methods and standards, the existence of a unique symbol set, key research and teaching topics and laws, rules and evidenced guidelines). In addition, the relationship between the impact of local contingencies and the degree of professionalism can be evaluated through an analysis of the extent of variation in the nature of IS in universities among the states of Australia over time and at present. Together, these two constructs will provide a means of tracking progress in the state and development of the IS discipline in Australian universities in the past and future, and will identify those issues that hinder progress.

The discipline of IS is subject to frequent change, including new research and teaching topics and methods. Pragmatism is one example of a recent development in the IS and related literature. The framework was examined to see whether it was capable of accommodating new developments in IS, such as pragmatism, without modification. As the framework remained robust as a result of this test, the results were interpreted as a further validation of the framework.

Future work will analyse the utility of the framework, based on its effectiveness to characterise the development of IS in Australian universities. This utility needs to consider more broadly whether change to IS can be fitted within the framework. The external view of the development of IS from those who are not IS academics will also need to be evaluated in future. Before applying the framework to examine the development of IS in other regions of the world, it might be necessary for further refinement, based on the outcomes from the framework's application to the Australian study.

\section{Acknowledgements}

I would like to thank a range of people for their valuable input on one or more aspects of this discussion and framework, including Rudi Hirschheim, Frank Land, Bob Smyth, Guy Gable, Shirley Gregor, Craig McDonald, Mike Metcalfe, Bob Zmud, Antony Bryant, Karlheinz Kautz and the anonymous reviewers.

\section{Select bibliography}

Ahituv, N. and Neumann, S. 1986, Principles of Information Systems for Management, 2nd edn, W. C. Brown, Dubuque, USA.

Al-Imamy, S. and Farhat, N. 2005, 'The MIS expectation gap in the UAE: industry expectations versus academic preparation', Journal of American Academy of Business, vol. 7, no. 2, pp. 78-85. 
Ariav, G., DeSanctis, G. and Moore, J. 1987, 'Competing reference disciplines for MIS research', Proceedings of the Eighth International Conference on Information Systems, Pittsburgh, Pennsylvania, pp. 455-8.

Avison, D. and Fitzgerald, G. 1991, 'Editorial', Journal of Information Systems, vol. 1, no. 1, pp. 1-3.

Bansler, J. 1989, 'Systems development research in Scandinavia: three theoretical schools', Scandinavian Journal of Information Systems, vol. 1, pp. 3-20.

Banville, C. and Landry, M. 1992, 'Can the field of MIS be disciplined?', in R. D. Galliers (ed.), Information Systems Research: Issues, Methods and Practical Guidelines, Blackwell Scientific Publications, Oxford, UK.

Baskerville, R. and Myers, M. 2002, 'Information systems as a reference discipline', MIS Quarterly, vol. 26, no. 1, pp. 1-14.

Baskerville, R. and Myers, M. 2004, 'Special issue on action research in information systems: making IS research relevant to practice-foreword', MIS Quarterly, vol. 28, no. 3, pp. 329-36.

Bauman, Z. 1992, Intimations of Postmodernity, Routledge, New York.

Becher, T. 1987, 'Disciplinary discourse', Studies in Higher Education, vol. 12, no. 3, pp. 261-74.

Becher, T. 1994, 'The significance of disciplinary differences', Studies in Higher Education, vol. 19, no. 2, pp. 151-61.

Benbasat, I. and Weber, R. 1996, 'Research commentary: rethinking "diversity" in information systems research', Information Systems Research, vol. 7, no. 4, pp. 389-99.

Benbasat, I. and Zmud, R. W. 1999, 'Empirical research in information systems: the practice of relevance', MIS Quarterly, vol. 23, no. 1, pp. 3-16.

Benbasat, I. and Zmud, R. W. 2003, 'The identity crisis within the IS discipline: defining and communicating the discipline's core properties', MIS Quarterly, vol. 27, no. 2, pp. 183-94.

Biglan, A. 1973, 'The characteristics of subject matter in different scientific areas', Journal of Applied Psychology, vol. 57, no. 3, pp. 195-203.

Brannick, T. and Coghlan, D. 2006, 'To know and do: academic and practitioners' approaches to management research', Irish Journal of Management, vol. 26, no. 2, pp. 1-23.

Boudreau, M., Gefen, D. and Straub, D. 2001, 'Validation in information systems research', MIS Quarterly, vol. 25, no. 1, pp. 1-16.

Bunge, M. 1979, 'Philosophical inputs and outputs of technology', The History of Philosophy and Technology, University of Illinois Press, Urbana. 
Bryant, A. 2006, Thinking Informatically, Edwin Mellen, Lampeter, UK.

Challa, C., Kasper, G. and Redmont, R. 2005, 'The accreditation process for IS programs in business schools', Journal of Information Systems Education, vol. 16 , no. 2 , pp. 207-16.

Checkland, P. and Holwell, S. 1998, Information, Systems and Information Systems-Making Sense of the Field, John Wiley \& Sons, Chichester.

Chubin, D. and Connolly, T. 1982, 'Research trails and science policies: local and extra-local negotiation of scientific work', in N. Elias, H. Martins and R. Whitley (eds), Scientific Establishments and Hierarchies, D. Reidel Publishing Company, Dordrecht, Holland, pp. 293-312.

Cule, P. E. and Senn, J. A. 1995, 'The evolution from ICIS 1980 to AIS 1995: have the issues been addressed', Proceedings of the Inaugural Americas Conference on Information Systems, Pittsburgh, 25-27 August, Session MP-14.

Culnan, M. J. 1987, 'Mapping the intellectual structure of MIS, 1980-1985: a co-citation analysis', MIS Quarterly, vol. 11, no. 3, pp. 341-53.

Culnan, M. J. and Swanson, E. B. 1986, 'Research in management information systems, 1980-1984: points of work and reference', MIS Quarterly, vol. 10, no 3, pp. 289-301.

Culnan, M. J., Swanson, E. B. and Keller, M. T. 1993, 'MIS research in the 1980s: shifting points of work and reference', Proceedings of the Twenty-Sixth Hawaii International Conference on Systems Sciences. Volume 3, IEEE Computer Society Press, Los Alamitos, California, pp. 597-606.

Darke, P., Shanks, G. and Broadbent, M. 1998, 'Successfully completing case study research: combining rigour, relevance and pragmatism', Information Systems Research, vol. 8, no. 4, pp. 273-89.

Denning, P., Comer, D., Gries, D., Mulder, M., Tucker, A., Turner, J. and Young, P. 1989, 'Computing as a discipline', Communications of the ACM, vol. 32, no. 1, pp. 9-23.

de Solla Price, D. 1961, Science Since Babylon, Yale University Press, New Haven. de Solla Price, D. 1963, Little Science, Big Science, Columbia University Press, New York.

de Solla Price, D. 1970, 'Citation measures of hard science, soft science, technology and non-science', in C. Nelson and D. Pollock (eds), Communication Among Scientists and Engineers, Health \& Co., Lexington, Mass., pp. $3-22$.

Dickson, G. W., Benbasat, I. and King, W. R. 1982, 'The MIS area: problems, challenges, and opportunities', Data Base, vol. 14, no. 1, pp. 7-12. 
Dixon-Woods, M., Agarwal, S., Jones, D., Young, B. and Sutton, A. 2005, 'Synthesising qualitative and quantitative evidence: a review of possible methods', Journal of Health Services Research \& Policy, vol. 10, no. 1, pp. 45-53.

Elias, N. 1982, 'Scientific establishments', in N. Elias, H. Martins and R. Whitley (eds), Scientific Establishments and Hierarchies, D. Reidel Publishing Company, Dordrecht, Holland, pp. 3-70.

Falkenberg, E. D., Hesse, W., Lindgreen, P., Nilsson, B. E., Oei, J. L. H., Rolland, C., Stamper, R. K., Van Assche, F. J., Verrijn-Stuart, A. A. and Voss, K. 1998, 'A framework of information system concepts', The FRISCO Report (web edition), viewed 28 October 1998 , $<$ ftp://leidenuniv.nl/pub/rul/fri-full.zip>

Farhoomand, A. F. 1992, 'Scientific progress of management information systems', in R. D. Galliers (ed.), Information Systems Research: Issues, Methods and Practical Guidelines, Blackwell Scientific Publications, Oxford, UK.

Fitzgerald, E. P. 1993, 'Success measures for information systems strategic planning', Journal of Strategic Information Systems, vol. 2, no. 3, pp. 335-50.

Fitzgerald, G. 2003, 'Information systems: a subject with a particular perspective, no more, no less', European Journal of Information Systems, vol. 12, no. 3, pp. $225-8$.

Foucault, M. 1977, 'Truth and power', in C. Gordon (ed.), Power/Knowledge: Selected Interviews \& Other Writings 1972-1977, Pantheon Books, pp. 109-33.

Frank, U. 2006, 'Towards a pluralistic conception of research methods in information systems research', Institut fur Informatik und Wirtschaftsinformatik Research Report No. 7, December, University of Duisburg-Essen, Germany.

Freeman, P. A. 1995, 'Effective computer science', ACM Computing Surveys, vol. 27, no. 1, pp. 27-9.

Galliers, R. D. 1992, 'Choosing information systems research approaches', in R.

D. Galliers (ed.), Information Systems Research: Issues, Methods and Practical Guidelines, Blackwell Scientific Publications, Oxford, UK.

Gorokhov, V. 1998, 'A new interpretation of technological progress', Society of Technology and Philosophy, vol. 4, no. 1.

Grant, R. A. 1991, 'Issues in conducting a field study of computerized work monitoring', Proceedings of the 1991 ACM SIGCPR Conference, Athens, Georgia, USA, 8-9 April, pp. 68-79. 
Gries, D. and Marsh, D. 1988, 'The 1986-1987 Taulbee Survey', Communications of the ACM, vol. 31, no. 8, pp. 984-91.

Gries, D., Walker, T. and Young, P. 1989, 'The 1988 Snowbird Report: a discipline matures', Communications of the ACM, vol. 32, no. 3, pp. 294-7.

Hartmanis, J. 1995a, 'The Turing Lecture, Computing Surveys Symposium on Computational Complexity and the Nature of Computer Science', ACM Computing Surveys, vol. 27, no. 1, pp. 5-15.

Hartmanis, J. 1995b, 'Response to the essays “On Computational Complexity and the Nature of Computer Science"', ACM Computing Surveys, vol. 27, no. 1, pp. 59-61.

Hevner, A., March, S., Park, J. and Ram, S. 2004, 'Design science in information systems research 1', MIS Quarterly, vol. 28, no. 1, pp. 75-105.

Hirschheim, R. 1992, 'Information systems epistemology: an historical perspective', in R. D. Galliers (ed.), Information Systems Research: Issues, Methods and Practical Guidelines, Blackwell Scientific Publications, Oxford, UK.

Hirschheim, R. and Klein, H. 2003, 'Crisis in the IS field? A critical reflection on the state of the discipline', Journal of the Association for Information Systems, vol. 4, no. 5, pp. 237-93.

Hirschheim, R., Klein, H. and Lyytinen, K. 1996, 'Exploring the intellectual structures of information systems development: a social action theoretic analysis', Accounting, Management and Information Technologies, vol. 6, no. 1-2, pp. 1-64.

Hjorland, B. 2005, 'Library and information science and the philosophy of science', Journal of Documentation, vol. 61, no. 1, pp. 5-11.

Hopcroft, J. E. 1987, 'Computer science: the emergence of a discipline', Communications of the ACM, vol. 30, no. 3, pp. 198-202.

Ihde, D. 2004, 'Has the philosophy of technology arrived? A state of-the-art review', Philosophy of Science, vol. 71, pp. 117-31.

Introna, L. 2003, 'Disciplining information systems: truth and regimes', European Journal of Information Systems, vol. 12, no. 3, pp. 235-40.

Kanellis, P. and Paul, R. J. 2005, 'User behaving badly: phenomena and paradoxes from an investigation into information systems misfit', Journal of Organizational and End User Computing, vol. 17, no. 2, pp. 64-92.

Kanungo, S. 1993, 'Information systems: theoretical development and research approaches', Information Systems, vol. 18, no. 8, pp. 609-19.

Kanungo, S. 2004, 'On the emancipatory role of rural information systems', Information \& People, vol. 17, no. 4, pp. 407-22. 
Keen, P. G. 1991, 'Relevance and rigor in information systems research: improving quality, confidence cohesion and impact', in H. E. Nissen, H. K. Klein and R. Hirschheim (eds), Information Systems Research: Contemporary Approaches and Emergent Traditions, Elsevier Science Publishers BV, North-Holland, Amsterdam, pp. 27-49.

King, J. L. 1993, 'Editorial notes', Information Systems Research, vol. 4, no. 4, pp. 291-8.

King, J. L. 1994, 'Rock and roll will never die', SIGOIS Bulletin, vol. 15, no. 1, pp. $25-8$.

King, J. L. and Lyytinen, K. (eds) 2006, Information Systems: The State of the Field, Wiley, Chichester, England.

Klein, H. K. and Hirscheim, R. 2006, 'Further reflections on the IS discipline: climbing the tower of Babel', in J. King and K. Lyytinen (eds), Information Systems: The State of the Field, Wiley, Chichester, England.

Klein, H. K., Hirschheim, R. and Nissen, H. 1991, 'A pluralist perspective of the information systems research arena', in H. E. Nissen, H. K. Klein and R. Hirschheim (eds), Information Systems Research: Contemporary Approaches and Emergent Traditions, Elsevier Science Publishers, North-Holland, Amsterdam.

Kolb, D. 1981, 'Learning styles and disciplinary differences', in A. Chickering (ed.), The Modern American College, Jossey Bass, San Francisco, Calif., pp. 232-55.

Kuhn, T. S. 1970, The Structure of Scientific Revolutions, 2nd edn, University of Chicago Press, Chicago.

Lakatos, I. 1970, 'Falsification and the methodology of scientific research programs', in I. Lakatos and A. Musgrove (eds), Criticism and the Growth of Knowledge, Cambridge University Press, Cambridge, UK, pp. 91-196.

Latour, B. 2003, 'Do you believe in reality: news from the trenches of the science wars', in R. Scharff and V. Dusek (eds), Philosophy of Technology: The Technological Condition, Blackwell Publishing Ltd, pp. 126-37.

Lee, A. S. 1989, 'A scientific methodology for MIS case studies', MIS Quarterly, vol. 13, no. 1, pp. 33-50.

Lee, A. S. 2001, 'Editor's comments', MIS Quarterly, vol. 25, no. 1, pp. iii-vii.

Martin, A. 2004, 'Addressing the gap between theory and practice: IT project design', Journal of Information Technology Theory and Application, vol. 6, no. 2, pp. 23-43.

Mingers, J. 2002, 'Real-izing information systems: critical realism as an underpinning philosophy for information systems', in L. Applegate, R. 
Galliers and J. I. DeGross (eds), Proceedings of the Twenty-Third International Conference on Information Systems, Barcelona, 15-18 December 2002, pp. 295-303.

Mingers, J. and Stowell, F. (eds) 1997, Information Systems: An Emerging Discipline?, McGraw-Hill, Maidenhead, Berkshire, UK.

Paul, R. 2002, 'Is information systems an intellectual subject?' , European Journal of Information Systems, vol. 11, no. 2, pp. 174-7.

Pitt, J. 2000, Thinking About Technology: Foundations of the Philosophy of Technology, Seven Bridges Press, New York.

Polanyi, M. 1958, Personal Knowledge: Towards a Post-Critical Philosophy, University of Chicago Press, Chicago.

Popper, K. R. 1959, The Logic of Scientific Discovery, Harper Torchbook, London, England.

Ramesh, R. and Rao, H. 2005, 'Foreword design science and information systems', Information Systems Frontiers, vol. 7, no. 3, p. 215.

Ridley, G. 1997, 'The role of conferences and refereed journals in Australian information systems research', Australian Journal of Information Systems, vol. 5, no. 1, pp. 69-82.

Ridley, G. 2006, 'Characterising information systems in Australia: developing and evaluating a theoretical framework', Australasian Journal of Information Systems, vol. 14, no.1, pp. 141-62.

Ridley, G., Goulding, P., Lowry, G. and Pervan, G. 1998, 'The Australian information systems research community: an analysis of mainstream publication outlets', The Australian Journal of Information Systems, vol. 5, no. 2, pp. 69-80.

Rip, A. 1982, 'The development of restrictedness in the sciences', in N. Elias, H. Martins and R. Whitley (eds), Scientific Establishments and Hierarchies, D. Reidel Publishing Company, Dordrecht, Holland, pp. 219-38.

Rorty, R. 1999, Philosophy and Social Hope, Penguin Books, London, UK.

Ruscio, K. 1987, 'Many sectors, many professionals', in B. Clarke (ed.), The Academic Profession, University of California Press, Berkeley.

Seddon, P. 1991, 'Information systems: towards a definition for the 1990s', Proceedings of the Second Annual Conference on Information Systems and Database Special Interest Group, Sydney, pp. 372-82.

Shinn, T. 1982, 'Scientific disciplines and organizational specificity: the social and cognitive configuration of laboratory activities', in N. Elias, H. Martins and R. Whitley (eds), Scientific Establishments and Hierarchies, D. Reidel Publishing Company, Dordrecht, Holland, pp. 239-66. 
Straub, D. W. and Carlson, C. L. 1989, 'Validating instruments in MIS research', MIS Quarterly, vol. 13, no. 2, pp. 147-64.

Sundin, O. and Johannisson, J. 2005, ‘Pragmatism, neo-pragmatism and sociocultural theory: communicative participation as a perspective in LIS', Journal of Documentation, vol. 61, no. 1, pp. 23-44.

Swanson, E. B. and Ramiller, N. C. 1993, 'Information systems research thematics: submission to a new journal, 1987-1992', Information Systems Research, vol. 4, no. 4, pp. 299-330.

Tardif, R. (ed.) 1989, The Penguin Macquarie Dictionary of Australian Education, Penguin, Ringwood, Victoria, Australia.

Verrijn-Stuart, A. (ed.) 2001, A Framework of Information System Concepts - The Revised FRISCO Report, web document (draft).

Walstrom, K. A., Hardgrave, B. C. and Wilson, R. L. 1995, 'Forums for management information systems scholars', Communications of the ACM, vol. 38, no. 3, pp. 93-107.

Wernick, P. and Hall, T. 2004, 'Can Thomas Kuhn's paradigms help us understand software engineering?', European Journal of Information Systems, vol. 13, no. 3, pp. 235-43.

Whitley, R. 1984a, 'The development of management studies as a fragmented adhocracy', Social Science Information, vol. 23, no. 4-5, pp. 775-818.

Whitley, R. 1984b, The Intellectual and Social Organization of the Sciences, Clarendon Press, Oxford, UK.

Wikgren, M. 2005, 'Critical realism as a philosophy and social theory in information science?', Journal of Documentation, vol. 61, no. 1, pp. 11-23.

Zahedi, F. 2004, 'Consolidation and learning in IS: managing the research knowledge base', Information Resources Management Journal, vol. 17, no. 2 , pp. 1-4. 